\title{
Influence of Hospital Nurse Staffing Levels on the Colorectal Cancer Evaluation Grades, Mortality, and Length of Stay
}

\author{
Kim, Yunmi ${ }^{1}$. Kim, Se Young ${ }^{2}$ \\ ${ }^{1}$ Professor, College of Nursing, Eulji University, Seongnam, Korea \\ ${ }^{2}$ Associate Professor, Department of Nursing, Changwon National University, Changwon, Korea
}

\begin{abstract}
Purpose: In Korea, cancer is the leading cause of death, and colorectal cancer accounts for a third of deaths caused by cancer. This study aimed to analyze the influence of hospital nurse staffing level on colorectal cancer evaluation grades, mortality rate, and the length of stay of patients who underwent surgery for colorectal cancer. Methods: Secondary data collected in 2016, 2018 from the Health Insurance Review and Assessment Service, was used to measure nurse staffing, based on the adjusted nursing grade in general units and was then categorized as adhering with or violating the Medical Service Act. The influence of the nurse staffing on colorectal cancer evaluation grades, and the mortality rate in 129 hospitals was analyzed using multivariate logistic regression and multivariate gamma regression, respectively, and its influence on length of stay was analyzed through hierarchical multiple regression. Results: Hospitals that adhered to the Medical Service Act in nurse staffing had significantly lower odds for poor colorectal cancer evaluation grades. Hospitals which nurse staffing adhered to the Medical Service Act had a significantly lower mortality rate than those that violated it $(B=-0.51, p=.019)$, and had a significantly shorter length of stay ( $\beta=-.19, p=.034)$. Conclusion: Improvement of nurse staffing levels, in compliance with the Medical Service Act is crucial to provide high-quality nursing services to patients undergoing colorectal cancer surgery and to decrease the mortality rate, and shorten the hospitalization period required for surgery and recovery.
\end{abstract}

Key Words: Hospitals; Nurses; Colonic neoplasms; Workforce

\section{INTRODUCTION}

\section{Necessity of the Study}

In the 1860s, Florence Nightingale evaluated the in-hospital mortality rate of hospitals located in London and reported that there was a large gap among hospitals. This provided an impetus to launch the field of quality evaluation of hospitals as well as the public disclosure of related findings [1]. In Korea, the Health Insurance Review and Assessment Service (HIRA) started evaluating drug reimbursement and hematopoietic stem cell organ transplants in 2001. The scope of its evaluations has subsequently expanded to include the cesarean section rate, acute stroke, cancer surgery, and surgical antibiotic pro- phylaxis [2]. Recently, the HIRA has disclosed the results of evaluations of patients' experiences. These findings are relevant in the field of nursing because a performance-based incentive system, in which health insurance payments are commensurate with the results of quality evaluations will be more stringently applied in the future [2].

The areas for which the HIRA has disclosed quality evaluation results include surgical procedures for patients with cancer, which is the leading cause of death in Korea. Data are available for liver cancer, colorectal cancer, stomach cancer, breast cancer, and lung cancer. Of these conditions, information regarding colorectal cancer has been disclosed by most hospitals [3]. Colorectal cancer ranks third in Korea among cancer-related causes of death. Additionally, the number of deaths from colorectal cancer per

Corresponding author: Kim, Se Young https://orcid.org/0000-0001-8127-7535

Department of Nursing, Changwon National University, 20 Changwondaehak-ro, Uichang-gu, Changwon 51140, Korea.

Tel: +82-55-213-3576, Fax: +82-55-213-3579, E-mail: sarakimk@changwon.ac.kr

Received: May 21, 2019 / Revised: Jul 15, 2019 / Accepted: Aug 23, 2019

This is an open access article distributed under the terms of the Creative Commons Attribution Non-Commercial License (http://creativecommons.org/licenses/ by-nc/3.0), which permits unrestricted non-commercial use, distribution, and reproduction in any medium, provided the original work is properly cited. 
100,000 population increased from 12.8 in 2006 to 16.5 in 2016 and 17.1 in 2017 [4]. The survival rate and survival duration of several types of cancer have increased due to the combination of their increasing incidence and advances in diagnostic and treatment methods. As a result, cancer is becoming a chronic disease that requires long-term management and incurs higher medical expenses [5]. Therefore, it is necessary to understand high-quality medical services and cost-effective interventions in cancer treatment and nursing care [6]. It has been reported that nurses perform interventions in the domains of basic physiological nursing (basic), safety, and complex physiological nursing (complex) for patients with colorectal cancer [7]. Furthermore, nurses not only help alleviate the discomfort caused by intestinal ostomy management, perineal and abdominal discomfort, sleep disorder, skin damage, bleeding, stenosis, and hernias, including intestinal ostomy care [8], but also provide education about self-care and support for patients with an intestinal ostomy [6]. Nurses provide discharge education, when patients' get discharged from the hospital. These interventions include nursing treatment, prognostic nursing care, psychological support and stability, complication and discomfort management, and daily routine management [9]. Appropriate nurse staffing levels should be maintained to satisfy the nursing needs of colorectal cancer patients and to minimize missed nursing activities.

The results of a meta-analysis showed that the mortality rate of patients increased by $8 \%$, whenever the number of patients for whom each shift nurse was expected to care increased by one [10,11]. A Korean study reported that compared to the general units of hospitals with fewer than 2.5 beds per nurse, the mortality rate of surgical patients increased by $57 \%, 78 \%$, and $199 \%$ in hospitals with $\geq 2.5$ and $<3.5$ beds, $\geq 3.5$ and $<4.5$ beds, $\geq 4.5$ beds per nurse, respectively [12]. Many other studies have shown that increased nurse staffing levels yielded favorable economic effects, such as shortened lengths of hospital stay and reduced medical costs needed for patients' recovery [11,13, 14]. However, even within a single country, nurse staffing levels and patient outcomes vary depending on hospital type, ownership, area, educational activities, etc. [10-12].

Korea's hospital nurse staffing levels remain low among Organization for Economic Co-operation and Development (OECD) countries, with 5.9 nurses (including nurse's aides) per 1,000 population in 2015 [15]. The Korean government introduced a policy of differentiated nursing grades in 1999, on the basis of the number of beds per nurse, with the intention to improve nurse staffing levels in hospitals. Positive changes have therefore taken place in large hospitals in metropolitan areas, as well as in public and educational foundation owned hospitals. However, provincial small and mid-size hospitals with a low bed occupancy rate have only infrequently showed changes in nursing grades [16]. Thus, in April 2018, the standard for the grades of provincial small and mid-size hospitals were changed from the number of beds per nurse to the number of patients per nurse. Moreover, projects to support nurses' labor costs will be included to general hospitals or smaller hospitals in county (gun) regions [17].

While some reports have stated that hospital nurse staffing levels can affect the health of surgical patients, others have analyzed the association of hospital nurse staffing levels with quality evaluation outcomes, the mortality rate, and length of stay among patients undergone colorectal cancer surgery. Therefore, this topic warrants attention.

\section{Purpose of Study}

This study aimed to investigate the comprehensive evaluation grades for the quality of medical services provided by Korean hospitals to colorectal cancer surgery patients. Moreover, factors such as the mortality rate after surgery, length of stay, and associations between these outcomes and hospital nurse staffing levels were examined. First, a comparative analysis of the comprehensive evaluation grade for colorectal cancer (hereinafter, colorectal cancer evaluation grade), mortality rate, and length of stay according to the characteristics of hospitals was performed. Next, the influence of hospital nurse staffing levels on the colorectal cancer evaluation grade and mortality rate was investigated. Finally, the influence of nurse staffing level on length of stay was analyzed.

\section{Conceptual Framework}

The conceptual framework used to analyze the influence of nurse staffing levels on the health outcomes of colorectal cancer patients in this study is based on Donabedian's "Structure-Process-Outcome" model for evaluation of medical services as well as research done by Cho [18], who empirically applied this model to their research on nurse staffing levels and patient outcomes. In addition, the HIRA colorectal cancer assessment model was used [5]. The characteristics of hospitals and nurse staffing levels were found to influence 17 process-related indicators, which accounted for $82 \%$ of the evaluation scores of colorectal cancer patients and $13 \%$ of their mortality rate and length of stay [5]. This study analyzed type, ownership, area, and nurse staffing level as structural factors of hospitals, and 
the results of colorectal cancer assessment, mortality rate, and length of stay as outcome-related factors, in order to quantify the direct effect of the nurse staffing level on the outcome variables.

\section{METHODS}

\section{Study Design}

This was a cross-sectional descriptive study that analyzed secondary data comprising combined information on the results of the sixth evaluation of the quality of colorectal cancer surgery disclosed by the HIRA, along with information on the characteristics of hospitals and the nursing grade in general units.

\section{Setting and Sample}

The present study collected data about 135 hospitals, for which the HIRA had performed quality evaluations. These hospitals performed colorectal surgery between January 1, 2016 and December 31, 2016. The 135 hospitals for which the results of the sixth round of evaluation for colorectal cancer surgery were disclosed, included 43 (100.0\%) out of a total of 43 tertiary hospitals, $86(28.9 \%)$ out of a total of 298 general hospitals, and $6(0.2 \%)$ out of a total of 2,942 hospitals [19]. Finally, this study analyzed tertiary hospitals and general hospitals, with the exclusion of data from the 6 hospitals that were poorly represented in the data set.

\section{Measurement Variables}

\section{1) Colorectal cancer evaluation grade}

The HIRA evaluated 20 indicators through the linkage of health insurance claim information, research data based on medical records, and death data of the Ministry of the Interior and Safety on adults, $(\geq 18$ years old $)$ who received colectomy due to primary colorectal cancer with confirmed adenocarcinoma between January 1, 2016 and December 31, 2016 [5]. The evaluation indicators consisted of structural ( 1 item about the distribution of professional personnel), process-related (8 items about diagnostic evaluation and the accuracy of medical records, 1 item about patient education, 6 items about chemotherapy, 2 items about radiotherapy), and outcome-related (mortality rate and length of stay) variables. For total evaluation scores of $\geq 90,80 \sim 89$, and 70 79 points, grades 1,2 , and 3 were assigned, respectively [5]. This study dichotomized the colorectal cancer evaluation grades, which were assigned based on the distribution of the evaluation grades, as grade 1 and grades $2 \sim 3$.

\section{2) Mortality rate}

The mortality rate was calculated using the number of patients by hospital that died during their hospital stay or within 30 days after colorectal resection surgery [5].

\section{3) Length of stay}

The length of stay was calculated, after a patients' casemix adjustment according to the Korean diagnosis-related groups that classifies patients based on disease and surgery types [5].

\section{4) Level of nurse staffing}

Hospital nurse staffing levels were measured using the nursing grade for general units [20]. According to this system, inpatient reimbursement rates per day are set according to grades assigned based on the number of beds per nurse in the general unit. The nursing grade system for general units bifurcates hospitals into two tiers. The higher tier consists of tertiary hospitals, and the lower tier includes general hospitals and other smaller medical institutions. As the grades are calculated based on this classification of institutions, this study standardized the grades according to the classification used for general hospitals as follows: grade $1,<2.5$ beds per nurse; grade $2, \geq 2.5 \sim<3.0$ beds per nurse; grade $3, \geq 3.0 \sim<3.5$ beds per nurse; grade $4, \geq 3.5 \sim<4.0$ beds per nurse; grade $5, \geq 4.0 \sim<4.5$ beds per nurse; grade $6, \geq 4.5 \sim 6.0$ beds per nurse; and grade $7, \geq 6.0$ beds per nurse. Additionally, grade 0 was assigned to grade 1 for tertiary hospitals $(<2.0$ beds per nurse) [12].

As the adjusted nursing grade refers to the number of beds per nurse in the general unit, it was dichotomized into grades $0 \sim 2$. These grades adhered to the regulation of 5 inpatients per 2 nurses specified in Article 38 of the Enforcement Regulation of the Medical Service Act [Annex 5], while grades 3 7 violated the Medical Service Act, based on the bed occupancy rate in 2014 (tertiary hospitals: $93.7 \%$, general hospitals: $78.5 \%$ ) [21].

\section{5) Characteristics of hospitals}

Hospitals were classified as tertiary or general hospitals according the types of medical referral system, and by ownership as public and educational foundation-owned hospitals or others. Additionally, they were divided into hospitals in Seoul and metropolitan cities (large cities) and hospitals in provincial (do) regions (small cities and rural areas). 


\section{Data Collection}

The colorectal cancer evaluation grade data (variables about colorectal cancer evaluation grade, mortality rate, and length of stay) were collected from the colorectal cancer evaluation site of the HIRA [3] in October 2018. Information on hospital characteristics (type, ownership, and area), including the nursing grade, was collected for each hospital from the "Find a hospital/pharmacy DB" tool of the HIRA [20] in the second quarter of 2016. The two data sets were merged based on the hospital name and address.

\section{Ethical Considerations}

This study used publicly released secondary data and attained a review exemption from the Institutional Review Board of Changwon University (1040271-201812-HR-034)

\section{Data Analysis}

For data on differences in the colorectal cancer evaluation grade, mortality rate, and length of stay according to the characteristics of hospitals, categorical variables were analyzed using Fisher's exact test. Continuous variables were analyzed with the independent t-test and the MannWhitney U test after checking the normality of the distribution. The influence of nurse staffing level on colorectal cancer evaluation grades was analyzed with multivariate logistic regression (evaluation grade $2 \sim 3=1$, grade $1=0$ ) and its influence on the mortality rate was analyzed using multivariate gamma regression [22]. Lastly, the influence of nurse staffing level on length of stay was analyzed using hierarchical multivariate linear regression.

\section{RESULTS}

\section{Characteristics of Hospitals}

A total of 129 hospitals were analyzed, including tertiary hospitals and 86 general hospitals. In terms of ownership type, 79 hospitals were public or owned by an educational foundation, while 50 had other ownership structures, including medical corporations. In total, 117 hospitals received grade 1 on the colorectal cancer evaluations, while 12 received grade 2 or grade 3 evaluations, respectively (Table 1).

\section{Evaluation Grade, Mortality Rate and Length of Stay by Hospital Characteristics}

All the $43(100.0 \%)$ tertiary hospitals received a grade of 1, while $12(14.0 \%)$ general hospitals received grades of $2 \sim 3$. These results indicate a significant difference between hospital types. Out of the hospitals that adhered to the Medical Service Act in nurse staffing, 85 (97.7\%) received a grade of 1 on the colorectal cancer evaluations. However, out of the hospitals that violated the Medical Service Act, $10(23.8 \%)$ received a colorectal cancer evaluation grade of 2 or 3 , indicating a significant difference $\left(x^{2}=15.54, p<\right.$ .001). The mortality rate of colorectal cancer patients did not vary significantly, depending on the characteristics of hospitals.

The average length of stay in tertiary hospitals was 14.0 days, while in general hospitals it was 19.6 days, indicating a significant difference between the hospital types $(\mathrm{t}=$ $-7.58, p<.001)$. The length of stay (16.4 days) in public and educational foundation owned hospitals was shorter than in other hospitals $(\mathrm{t}=-4.37, p<.001)$, and the length of stay

Table 1. Colon Cancer Evaluation Grade, Mortality Rate, and Length of Stay by Hospital Characteristics

$(N=129)$

\begin{tabular}{|c|c|c|c|c|c|c|c|c|c|}
\hline \multirow{3}{*}{ Characteristics } & \multirow{3}{*}{ Categories } & \multirow{3}{*}{$\mathrm{n}$} & \multicolumn{2}{|c|}{$\begin{array}{c}\text { Colon cancer } \\
\text { evaluation grade }\end{array}$} & \multirow{3}{*}{$\begin{array}{l}x^{2} \\
(p)\end{array}$} & \multirow{3}{*}{$\begin{array}{c}\begin{array}{c}\text { Mortality } \\
\text { rate }\end{array} \\
\mathrm{M} \pm \mathrm{SD}\end{array}$} & \multirow{3}{*}{$\begin{array}{l}\mathrm{U} \\
(p)\end{array}$} & \multirow{3}{*}{$\begin{array}{c}\begin{array}{c}\text { Length of } \\
\text { stay }\end{array} \\
\mathrm{M} \pm \mathrm{SD}\end{array}$} & \multirow{3}{*}{$\begin{array}{c}\mathrm{t} \\
(p)\end{array}$} \\
\hline & & & 1 & $2 \sim 3$ & & & & & \\
\hline & & & $\mathrm{n}(\%)$ & $\mathrm{n}(\%)$ & & & & & \\
\hline \multirow[t]{2}{*}{ Hospital type } & Tertiary hospital & 43 & $43(100.0)$ & $0(0.0)$ & $6.62^{\dagger}$ & $1.39 \pm 1.37$ & 1822.00 & $14.0 \pm 2.28$ & -7.58 \\
\hline & General hospital & 86 & $74(86.0)$ & $12(14.0)$ & $(.010)$ & $2.82 \pm 4.14$ & $(.891)$ & $19.6 \pm 4.52$ & $(<.001)$ \\
\hline \multirow[t]{2}{*}{ Ownership } & Public and educational foundation & 79 & $71(89.9)$ & $8(10.1)$ & $0.16^{\dagger}$ & $1.67 \pm 2.36$ & 1729.50 & $16.4 \pm 4.02$ & -4.37 \\
\hline & Others & 50 & $46(92.0)$ & $4(8.0)$ & $(.765)$ & $3.40 \pm 4.68$ & $(.227)$ & $19.9 \pm 4.95$ & $(<.001)$ \\
\hline \multirow[t]{2}{*}{ Urbanization } & Large cities & 70 & $64(91.4)$ & $6(8.6)$ & $0.10^{\dagger}$ & $1.71 \pm 2.11$ & 1843.50 & $17.6 \pm 5.24$ & -0.47 \\
\hline & Small cities and rural area & 59 & $53(89.8)$ & $6(10.2)$ & $(.771)$ & $3.09 \pm 4.60$ & $(.287)$ & $17.9 \pm 4.01$ & $(.639)$ \\
\hline \multirow{2}{*}{$\begin{array}{l}\text { Nurse staffing } \\
\text { level }\end{array}$} & Adherence & 87 & $85(97.7)$ & $2(2.3)$ & $15.54^{\dagger}$ & $1.72 \pm 2.48$ & 1601.00 & $16.3 \pm 4.39$ & -5.48 \\
\hline & Violation & 42 & $32(76.2)$ & $10(23.8)$ & $(<.001)$ & $3.62 \pm 4.85$ & $(.248)$ & $20.7 \pm 3.94$ & $(<.001)$ \\
\hline
\end{tabular}

${ }^{\dagger}$ Fisher's exact test. 
(16.3 days) in hospitals that adhered to the Medical Service Act was found to be significantly shorter than (20.7 days) in hospitals that violated the Medical Service Act $(\mathrm{t}=-5.48$, $p<.001$ ) (Table 1).

\section{Nurse Staffing Levels, Colorectal Cancer Evaluation Grade and Mortality Rate}

The likelihood of receiving a grade of 2 or above was significantly lower (by $89 \%$ ) in hospitals with an ownership type of others, as compared to public and educational foundation $(\mathrm{OR}=0.11,95 \% \mathrm{CI}=0.02 \sim 0.63, p=.013)$. Similarly, the likelihood of receiving a grade of 2 or above for hospitals that adhered to the Medical Service Act, was significantly lower, (by 97\%) in comparison to hospitals that violated the Medical Service Act $(\mathrm{OR}=0.03,95 \% \mathrm{CI}=0.01 \sim 0.16, p<$ .001). Based on the results of the analysis, a multivariate gamma regression model was fit with statistical significance, since the total deviance was less than 4 (deviance) $\mathrm{df}=0.702, \log$-likelihood=-174.56, $\left.x^{2}=40.62, p<.001\right)$. The mortality rate of general hospitals was significantly higher than that of tertiary hospitals, $(\mathrm{B}=0.58, p=.021)$ while the mortality rate of hospitals that adhered to the Medical Service Act was significantly lower than those that violated the Medical Service Act $(\mathrm{B}=-0.51, p=.019)$ (Table 2).

\section{Nurse Staffing Levels and Length of Stay}

There were no issues with conducting a linear regression analysis for this variable. Moreover, the variance inflation factor did not reveal the problem of multi-collinearity (Variance Inflation Factor, VIF=1.476). The result of residual analysis through the Durbin-Watson test was 1.87 , which met the equal variance assumption. Among the characteristics of hospitals, in model 1, where hospital type, ownership, and urbanization were input, type (general hospitals; $\beta=.50, p<.001$ ) and ownership (others; $\beta=.16, p=$ .047) explained $32 \%$ of variation in length of stay $(\mathrm{F}=21.16$, $p<.001$ ). In model 2 , where nurse staffing level was added as an independent variable, type (general hospitals; $\beta=.44$, $p<.001$ ) and nurse staffing level (adherence; $\beta=-.19, p=$ .034 ) had a significant influence on length of stay. Moreover, nurse staffing level explained $34 \%$ of variation in length of stay $(\mathrm{F}=17.48, p<.001)$. In other words, adding nurse staffing level to the model increased its explanatory power by $2 \%$ (Table 3 ).

\section{DISCUSSION}

This study was conducted to analyze the influence of hospitals' nurse staffing level on the quality of care received by colorectal cancer patients, mortality rate, and length of stay using secondary data released by the HIRA.

An adjusted nursing grade of 3 or more is referred to as a situation wherein nurses care for more inpatients than the standard prescribed in the Medical Service Act [21]. Such hospitals were found to have a lower likelihood of obtaining a grade of 1 in the colorectal cancer evaluation. Hospital nurse staffing levels are believed to affect colorectal cancer evaluation scores as mortality rate and length of stay are included in the colorectal cancer evaluation items and nurses' activities are included in the various process indicators [5]. For instance, the evaluation standard of the "pain before surgery evaluation rate" index is a measure to evaluate pain and is used by doctors and nurses, right from the patients' first preoperative visit to surgery. The evaluation standard for the "family cancer history" index is for doctors and nurses to check the patients'

Table 2. Logistic and Gamma Regression Analysis of the Colon Cancer Evaluation Grade and Mortality Rate

$(N=129)$

\begin{tabular}{|c|c|c|c|c|c|c|c|}
\hline \multirow[t]{2}{*}{ Variables } & \multirow[t]{2}{*}{ Categories } & \multicolumn{2}{|c|}{$\begin{array}{c}\text { Colon cancer } \\
\text { evaluation grade }\end{array}$} & \multicolumn{4}{|c|}{ Mortality rate } \\
\hline & & OR (95\% CI) & $p$ & B & SE & Wald & $p$ \\
\hline Hospital type & $\begin{array}{l}\text { General hospital } \\
\text { (ref.: tertiary hospital) }\end{array}$ & - & - & 0.58 & 0.25 & 5.35 & .021 \\
\hline Ownership & $\begin{array}{l}\text { Others } \\
\text { (ref.: public and educational foundation) }\end{array}$ & $0.11(0.02 \sim 0.63)$ & .013 & 0.24 & 0.22 & 1.13 & .288 \\
\hline Urbanization & $\begin{array}{l}\text { Small cities and rural area } \\
\text { (ref.: large cities) }\end{array}$ & $1.73(0.37 \sim 8.04)$ & .485 & 0.28 & 0.18 & 2.45 & .118 \\
\hline \multirow[t]{2}{*}{$\begin{array}{l}\text { Nurse staffing } \\
\text { level }\end{array}$} & $\begin{array}{l}\text { Adherence } \\
\text { (ref.: violation) }\end{array}$ & $0.03(0.01 \sim 0.16)$ & $<.001$ & -0.51 & 0.22 & 5.53 & .019 \\
\hline & & & & \multicolumn{4}{|c|}{$x^{2}=40.62(p<.001)$} \\
\hline
\end{tabular}

$\mathrm{OR}=$ odds ratio; $\mathrm{CI}=$ confidence interval; $\mathrm{SE}=$ standard error; $\mathrm{LL}=$ log-likelihood; $\mathrm{df}=$ degree of freedom. 
Table 3. Hierarchical Regression Analysis for the Influence of Nurse Staffing Level on Length of Stay

$(N=129)$

\begin{tabular}{|c|c|c|c|c|c|c|c|c|c|c|c|}
\hline \multirow{2}{*}{ Variables } & \multirow{2}{*}{ Categories } & \multicolumn{5}{|c|}{ Model 1} & \multicolumn{5}{|c|}{ Model 2} \\
\hline & & B & SE & $\beta$ & $\mathrm{t}$ & $p$ & B & SE & $\beta$ & $\mathrm{t}$ & $p$ \\
\hline Hospital type & $\begin{array}{l}\text { General hospital } \\
\text { (ref.: tertiary hospital) }\end{array}$ & 5.01 & 0.81 & .50 & 6.22 & $<.001$ & 4.36 & 0.85 & .44 & 5.11 & $<.001$ \\
\hline Ownership & $\begin{array}{l}\text { Others } \\
\text { (ref.: public and educational foundation) }\end{array}$ & 1.56 & 0.78 & .16 & 2.00 & .047 & 1.01 & 0.81 & .10 & 1.24 & .217 \\
\hline Urbanization & $\begin{array}{l}\text { Small cities and rural area } \\
\text { (ref.: large cities) }\end{array}$ & -0.79 & 0.70 & -.08 & -1.13 & .261 & -0.85 & 0.69 & -.09 & -1.23 & .222 \\
\hline $\begin{array}{l}\text { Nursing staffing } \\
\text { levels }\end{array}$ & $\begin{array}{l}\text { Adherence } \\
\text { (ref.: violation) }\end{array}$ & - & - & - & - & & -1.87 & 0.87 & -.19 & -2.15 & .034 \\
\hline $\mathrm{R}^{2}\left(\Delta \mathrm{R}^{2}\right)$ & & & & .34 & & & & & $.36(.0$ & & \\
\hline Adjusted $\mathrm{R}^{2}$ & & & & .32 & & & & & .34 & & \\
\hline $\mathrm{F}(p)$ & & & & $16(<$ & $01)$ & & & & $48(<$ & 001) & \\
\hline
\end{tabular}

$\mathrm{SE}=$ standard error.

family history of cancer, while the evaluation standard for the "intestinal ostomy management education execution rate" index is for details of intestinal stoma management, including intestinal fistula skin management, and is recorded in patients' medical records [5]. As the 17 process indicators, (out of the 20 colorectal cancer evaluation indicators) are evaluated based on whether healthcare services have been provided to colorectal cancer surgical patients using a standardized protocol, it is predicted that maintenance of appropriate levels of nurse staffing, are related with attaining higher scores [13]. According to U.S. News \& World Report, hospitals with the highest performance in colorectal cancer surgery were those that had high nursing staffing levels, and were certified as "Magnet hospitals"[13].

The mortality rate of hospitals that adhered to the Medical Service Act was found to be significantly lower than hospitals that violated it. This finding is in line with the results of previous domestic and international studies that have reported that higher hospital nursing staffing levels were associated with lower inpatient mortality rates after admission of surgical patients, including those with colorectal cancer [10-12]. In other words, if the nurse staffing levels specified in the Medical Service Act are adhered to, the mortality rate of colorectal cancer patients can be greatly reduced. This conclusion is supported by the fact that the mortality rate of surgical patients in California, USA decreased by $13 \%$ two years after a law mandating minimum nurse staffing levels was enacted in 2004. The rate of decrease was greater than what was observed in New Jersey and Pennsylvania, where the minimum nurse staffing level had not been enacted [23]. Moreover, the decrease in $12 \%$ in the mortality rate of inpatients, reported after the mandatory nurse staffing standard was implemented in Queensland, Australia, further confirms our argument [10]. These international findings imply that beneficial impacts of ensuring adequate nurse staffing can be achieved in Korea, too.

This study demonstrated that in hospitals that adhered to the Medical Service Act, the average length of stay was shorter by 1.87 days than in hospitals that violated the Medical Service Act. This is because appropriate levels of nurse staffing enable the nursing needs of surgical patients to be satisfied and decrease the frequency of missed nursing activities [24]. Moreover, it promotes patients' early recovery by reducing complications such as pneumonia or sepsis [12]. An international study also reported that higher hospital nurse staffing levels shortened the length of stay of surgical patients [25,26]. On the other hand, a domestic study with 22,289 patients who had had knee or hip joint surgery, found that the length of stay in hospitals with adjusted nursing grades of 2 3, 4 5, and $6 \sim 7$ were longer by $6.54,7.59$, and 15.99 days than those with grades of $0 \sim 1$, respectively [14]. The mean length of stay in Korean hospitals is about 16.1 days in 2015, which is two times the OECD average of 8.2 days [27]. It has therefore been suggested that improving nurse staffing levels will be helpful to safely shorten unnecessarily long hospital stays [10].

The current study confirmed that hospitals that complied with the nurse staffing levels specified in the Medical Service Act had higher-quality colorectal cancer care, a significantly lower mortality rate, as well as a shorter length of stay for recovery. From these findings, the following conclusions can be drawn. First, in terms of policy, patients' safety should be ensured by increasing enforcement 
of nurse staffing regulations, so that all hospitals comply with the nurse staffing levels specified in the Medical Service Act $[10,27,28]$. Furthermore, based on the results of this study, the nurse staffing level should be added to the structural indicators that are used to evaluate the quality of care in colorectal cancer. At present, the structural indicators in hospitals include presence/absence of specialists in surgery, hematology-oncology, and pathology departments. However, the USA takes into account the presence of full-time Intensive Care Unit (ICU) specialists in hospitals, their nurse staffing level, as well as the label of a "Magnet hospital", in the selection of excellent hospitals for colorectal surgery [13]. Furthermore, in Korea, the nurse staffing level is utilized as a structural indicator to evaluate the quality of hemodialysis care. Therefore, it should also be considered when developing colorectal cancer related policies. Clinical nursing managers should find ways to sufficiently reflect the value of nursing in the performance-based incentive system applied in various areas, including colorectal cancer, which is executed by the government and the HIRA. Nurses caring for colorectal cancer surgical patients should understand and implement the process standard of care for colorectal cancer. Moreover, additional research with a greater sample size should be conducted on the influence of nurse staffing levels on process-related indicators, patient health, and resource consumption such as length of stay or medical costs. In addition, there is a need for research to develop ways of improving the imbalanced distribution of nurses across diverse hospitals and areas.

This study had limitations in its ability to reflect the influence of individual characteristics (sex, age, severity of disease, hospitalization route, income level, etc.) of colorectal cancer patients on mortality and length of stay. Additionally, this study was unable to take the nurse staffing level of operating rooms and the ICU, or nurses' education level and clinical experience into consideration. Further research is needed to clarify the influence of nurse staffing levels on the quality of medical services undergoing colorectal cancer surgery, mortality rate, and length of stay, using datasets constructed on the basis of National Health Insurance administrative data at the individual level. The results of such research could then be compared with research conducted at the hospital level.

\section{CONCLUSION}

This study confirmed that hospital nurse staffing levels should be maintained or improved, in compliance with the Medical Service Act. This will help provide high-qual- ity nursing services to surgical patients, reduce the surgery-related mortality rate, and shorten the length of stay. In addition, adherence to the Medical Service Act will help to reduce variations in the nurse staffing level across areas and hospitals. In the future, the nurse staffing level should be included in the structure related indicators for colorectal cancer evaluation. Additionally, research data and methodologies need to be developed to analyze the influence of the nurse staffing level on patient outcomes, length of stay, medical cost, and nurse outcomes in various areas, including but not limited to colorectal cancer. The nursing community should work together to make proactive efforts to ensure that the value of nursing is reflected in the performance-based incentive system.

\section{CONFLICTS OF INTEREST}

The authors declared no conflict of interest.

\section{AUTHORSHIP}

Study conception and design acquisition - KY and KSY; Data collection, Analysis, and interpretation of the data - KY; Drafting and critical revision of the manuscript - KY and KSY.

\section{ACKNOWLEDGEMENT}

This research was supported by the Basic Science Research Program through the National Research Foundation of Korea (NRF) funded by the Ministry of Education (grant number: 2017R1D1A1 B03033771)

\section{REFERENCES}

1. Marshall MN, Shekelle PG, Davies HTO, Smith PC. Public reporting on quality in the United States and the United Kingdom. Health Affairs. 2003;22(3):134-48.

https://doi.org/10.1377/hlthaff.22.3.134

2. Lee KD. Efficient quality management by evaluating adequacy. HIRA Policy Trends. 2014;8(4):71-85.

3. Health Insurance Review and Assessment Service. Find a hospital evaluation. [Internet]. Wonju: Health Insurance Review and Assessment Service; 2018 [cited 2018 October 1]. Available from:

https://www.hira.or.kr/re/diag/getDiagEvlList.do?pgmid= HIRAA030004000100

4. Statistics Korea. 2017 Annual report on the causes of death statistics. Daejeon: Statistics Korea; 2018 October. Report No.: 11-1240000-000028-10.

5. Health Insurance Review and Assessment Service. 6th Quality evaluation report of colon cancer. Wonju: Health Insurance Review and Assessment Service; 2018 June.

6. Han KS, Khim SY, Lee SJ, Park ES, Park Y-J, Kim JH, et al. 
Family functioning and quality of life of the family care-giver in cancer patients. Journal of Korean Academy of Nursing. 2006;36(6):983-91. https://doi.org/10.4040/jkan.2006.36.6.983

7. Moon KH, Ahn MJ, Kim PJ, Park JY, Kim MA, Park IS, et al. Analysis of nursing interventions frequently used with cancer patients. Journal of Korean Clinical Nursing Research. 2009; 15(1):107-22

8. Lee HO. Empirical study: adjustment of persons with a permanent colostomy following stoma surgery [master's thesis] Seoul: Ewha Womans University; 1998.

9. Ju AR, Yeoum SG, Park KS. The nursing needs of post-surgical colon cancer patients at discharge. Journal of Korean Academy of Fundamentals of Nursing. 2009;16(4):392-401.

10. Ball JE, Bruyneel L, Aiken LH, Sermeus W, Sloane DM, Rafferty AM, et al. Post-operative mortality, missed care and nurse staffing in nine countries: a cross-sectional study. International Journal of Nursing Studies. 2018;78;10-15. https://doi.org/10.1016/j.ijnurstu.2017.08.004

11. Kane RL, Shamliyan T, Mueller C, Duval S, Wilt TJ. Nurse staffing and quality of patient care. Evidence Report/Technology Assessment. Rockville, MD: Agency for Healthcare Research and Quality (US); 2007 March. Report No.: 07-E005.

12. Kim Y, Cho S-H, June KJ, Shin SA, Kim J. Effects of hospital nurse staffing on in-hospital mortality, pneumonia, sepsis, and urinary tract infection in surgical patients. Journal of Korean Academy of Nursing. 2012;42(5):719-29. https://doi.org/10.4040/jkan.2012.42.5.719

13. George A, Adams Z, Majumder A, Martin G, Harder B, Dougherty GB. Methodology U.S. news \& world report 2018-2019 best hospitals procedures \& conditions ratings. U.S. News \& World Report. Washington, DC: U.S. News \& World Report, L.P.; 2018 August.

14. Kim Y, Kim S-H, Ko Y. Effect of nurse staffing variation and hospital resource utilization. Nursing \& Health Sciences. 2016 18(4):473-80. https:// doi.org/10.1111/nhs.12294

15. Ministry of Health and Welfare, Korea Institute for Health and Social Affairs. OECD health statistics 2017(abstract). Seoul: Kyungsungmedia; 2017. p. 3.

16. Kim YM, Kim, J, June KJ, Ham EO. Changing trend in grade of nursing management fee by hospital characteristics: 2008-2010. Journal of Korean Clinical Nursing Research. 2010;16(3):99-109.

17. Paek SJ. Apply a penalty of $10 \%$ deduction of hospitalization fees for hospitals that do not report nursing staff. Dailymedi. 2019 [cited 2019 June 16]. Available from: http://www.dailymedi.com/detail.php?number=843331\&th $\mathrm{read}=22 \mathrm{r} 01$

18. Cho SH. Nurse staffing and adverse patient outcomes [dissertation]. Ann Arbor, Michigan: University of Michigan; 2002.

19. Statistics Korea. Number of hospital by the type: 2008-2016. [Internet]. Daejeon: Statistics Korea; 2018 [cited 2018 September 2]. Available from: http://210.179.230.152:8083/statHtml/statHtml.do?orgId=358 \&tblId=DT_IEB002_4\&conn_path=I2

20. Health Insurance Review and Assessment Service. Find a hospital/pharmacy [Internet]. Wonju: Health Insurance Review and Assessment Service; 2016 [cited 2016 June 1]. Available from: https://www.hira.or.kr/rd/hosp/getHospList.do?pgmid= HIRAA030002020000

21. Shin YS, Hwang DK, Kim SU, Park GR. Research on improvement plan of differentiated inpatient nursing fees according to the level of nursing manpower staffing. Sejong: Korea Institute for Health and Social Affairs; 2015 December. Report No.: G000CU1-2015-200

22. Lee IH. Easy flow regression analysis. Seoul: Hannarae; 2014. p. $434-43$.

23. Aiken LH. The California nurse staffing mandate: implications for other states. LDI Issue Brief. 2010;15(4):1-4.

24. Cho S-H, Kim Y-S, Yeon KN, You S-J, Lee ID. Effects of increasing nurse staffing on missed nursing care. International Nursing Review. 2015;62(2):267-74. https://doi.org/10.1111/inr.12173

25. Needleman J, Buerhaus P, Mattke S, Stewart M, Zelevinsky K. Nurse-staffing levels and the quality of care in hospitals. The New England Journal of Medicine. 2002;346(22):1715-22. https://doi.org/10.1056/nejmsa012247

26. Tschannen D, Kalisch BJ. The effect of variations in nurse staffing on patient length of stay in the acute care setting. Western Journal of Nursing Research. 2008;31(2):153-70. https://doi.org/10.1177/0193945908321701

27. Hae SH. Nursing workforce issues and improvement strategies in Korea. Oral presented at: The Policy forum of guarantee national health rights and improve quality of nursing; 2019 June 12; Seoul.

28. Kim Y, Kim J, Shin SA. Relationship between the legal nurse staffing standard and patient survival after perioperative cardiac arrest: a cross-sectional analysis of Korean administrative data. International Journal of Nursing Studies. 2019;89:104-11. https://doi.org/10.1016/j.ijnurstu.2018.09.012 